\title{
Scalable Production of Graphene Oxide Using a 3D-Printed Packed- Bed Electrochemical Reactor with a Boron-Doped Diamond Electrode
}

\author{
Sean E. Lowe, ${ }^{\dagger}$ Ge Shi, ${ }^{\dagger}$ Yubai Zhang, ${ }^{\dagger}$ Jiadong Qin, ${ }^{\dagger}$ Shujun Wang, ${ }^{\dagger}$ Alexander Uijtendaal, ${ }^{\dagger}$
} Jiqing Sun, ${ }^{\dagger}$ Lixue Jiang, ${ }^{\dagger}$ Shuaiyu Jiang, ${ }^{\dagger}$ Dongchen Qi, ${ }^{\ddagger},{ }^{\ddagger}$ Mohammad Al-Mamun, ${ }^{\dagger \odot}$ Porun Liu, ${ }^{\dagger \odot}$ Yu Lin Zhong, ${ }^{*} \dagger \odot$ and Huijun Zhao, ${ }^{*}$

${ }^{\dagger}$ Centre for Clean Environment and Energy, School of Environment and Science, Gold Coast Campus, Griffith University, Gold Coast, Queensland 4222, Australia

${ }^{\ddagger}$ School of Chemistry, Physics and Mechanical Engineering, Queensland University of Technology, Brisbane, Queensland 4001, Australia

${ }^{\S}$ Department of Chemistry and Physics, La Trobe University, Melbourne, Victoria 3086, Australia

Supporting Information
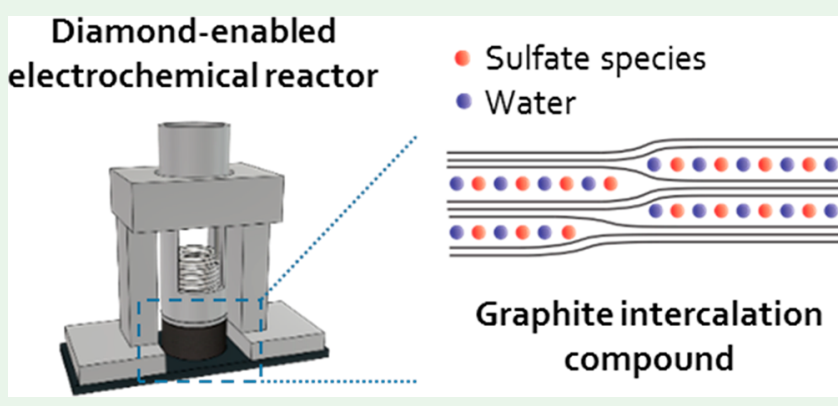

Oxygen functionalities

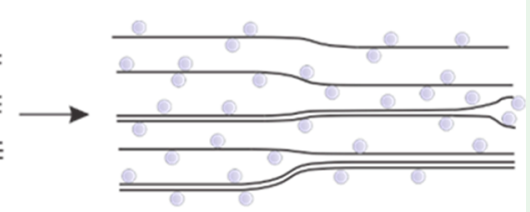

Graphite oxide

ABSTRACT: Although graphene oxide (GO) has shown enduring popularity in the research community, its synthesis remains cost prohibitive for many of its demonstrated applications. While significant progress has been made on developing an electrochemical route to $\mathrm{GO}$, existing methods have key limitations regarding their cost and scalability. To overcome these challenges, we employ a combination of commercially available fused-deposition-modeling-based 3D printing and highly robust boron-doped diamond with a wide electrochemical potential window to fabricate a scalable packed-bed electrochemical reactor for GO production. The scalability of the reactor along the vertical and lateral dimensions was systematically demonstrated to facilitate its eventual industrial application. Our current reactor is cost-effective and capable of producing electrochemically derived GO (EGO) on a multiple-gram scale. By oxidizing flake graphite directly in an $11.6 \mathrm{M}$ sulfuric acid electrolyte, the production of EGO was streamlined to a one-step electrochemical reaction, followed by a simple water-wash purification. Almost all of the converted graphite oxide can be recovered, and the final mass yield is typically $155 \%$ of the starting graphite material. The as-produced EGO is dispersible in water and other polar organic solvents (e.g., ethanol and dimethylformamide) and can be exfoliated down to predominantly single-layered GO. Through a detailed study of the product intermediates, the graphite was found to first form a stage III or higher graphite intercalation compound, followed by electrochemical oxidation proceeding from the top of the packed graphite bed down. The EGO can be easily deoxygenated with low-temperature thermal annealing $\left(<200{ }^{\circ} \mathrm{C}\right)$ to produce thermally converted EGO with significantly enhanced conductivity, and its promising application as a conductive nanofiller in lithium-ion battery cathodes was demonstrated. The simplicity, cost-effectiveness, and unique EGO properties make our current method a viable contender for large-scale synthesis of GO.

KEYWORDS: graphene oxide, electrochemistry, boron-doped diamond, 3D printing, packed-bed electrochemical reactor

\section{INTRODUCTION}

Graphene oxide (GO) is a graphene derivative decorated with various oxygen functional groups (e.g., hydroxyl, epoxy, carbonyl, and carboxyl groups $)^{1}$ which can be removed by chemical or other means to produce a conductive reduced GO (rGO). GO and rGO have both seen immense research and industrial interest for their applications in a range of fields, including conductive inks, ${ }^{2}$ bio- and chemosensors, ${ }^{3,4}$ cell/ tissue scaffolds, ${ }^{5}$ electrocatalysts, ${ }^{6,7}$ composite materials and polymers, $^{8}$ energy storage, ${ }^{9}$ and other applications not requiring defect-free graphene. ${ }^{10}$ Chemical oxidation of graphite, typically via a modification of the Hummers

Received: November 22, 2018

Accepted: January 9, 2019 
A Weight pressing down on graphite

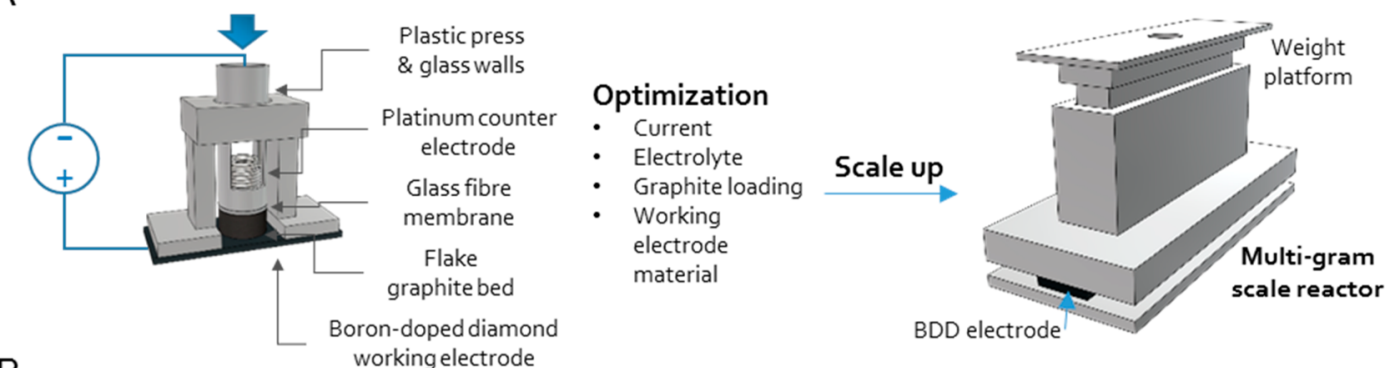

B working electrode

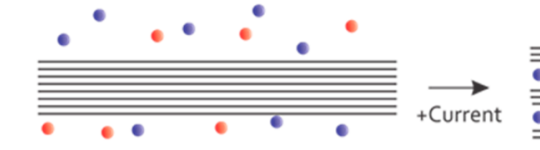

Graphite electrode in electrolyte

- Sulfate species $\left(\mathrm{H}_{2} \mathrm{SO}_{4}, \mathrm{HSO}_{4}{ }^{-}\right)$- Water

- Oxygen functionalities (e.g. - $\mathrm{OH}$ ) $\mathrm{O}_{21} \mathrm{CO}$, or $\mathrm{CO}_{2}$ gas

C

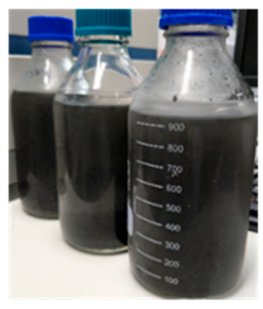

D

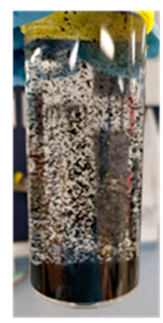

Stage III-IV graphite intercalation compound

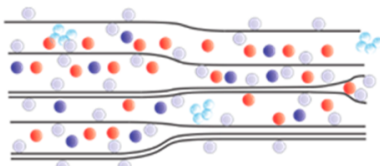

Further oxidized graphite

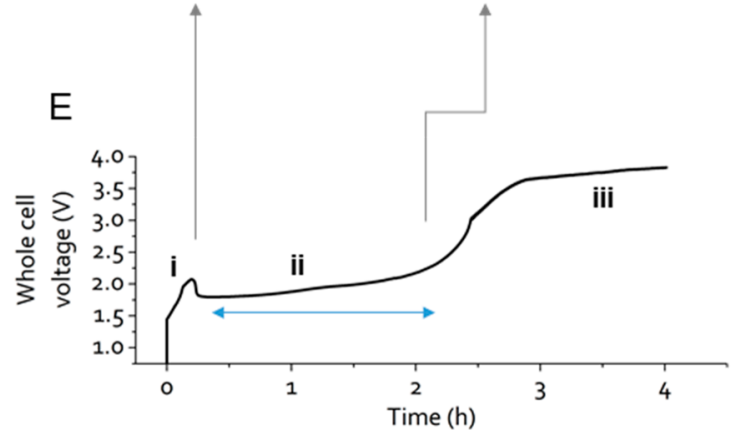

Figure 1. (A) Illustration of the small-scale tubular reactor used for fundamental studies of graphite oxidation. The packed-bed reactor was optimized for several variables and then scaled to produce $6 \mathrm{~g}$ of EGO. (B) Schematic overview of the graphite oxide forming mechanism (further postprocessing steps are shown in Figure S21). (C) Typical appearance of the as-prepared, presonication graphite oxide from the larger-scale reactor (after shaking, with a high concentration of $6 \mathrm{mg} / \mathrm{mL}$ ). (D) Typical appearance of $\sim 60 \mathrm{mg}$ of the presonication graphite oxide (after shaking the $125 \mathrm{~mL}$ bottle and waiting several seconds). (E) Typical galvanostatic charging curve, exhibiting a rising voltage region, i, associated with graphite intercalation, a slowly rising region, ii, associated with oxygen addition to the graphite, and a final plateau, iii, associated with oxygen evolution. Data shown are for the $40 \mathrm{mg}$ starting graphite, $16 \mathrm{~mA}$ constant current, and $11.6 \mathrm{M}$ sulfuric acid electrolyte condition. The arrows in part $\mathrm{E}$ indicate hypothesized structures at different time points.

method, ${ }^{11}$ is the most prominent approach to GO synthesis. Although this method is currently employed in industry, it has several key limitations. ${ }^{12,13}$ The process employs a dangerous oxidant, manganese heptoxide created when $\mathrm{KMnO}_{4}$ is mixed with concentrated sulfuric acid, and requires cooling to avoid explosion. $^{14}$ After the reaction, the GO product contains significant metal-ion contaminants, which are difficult, costly, and time-consuming to remove. These factors collude to make chemically derived GO (CGO) cost-prohibitive for many of its demonstrated applications. ${ }^{12}$

An alternative approach to producing GO employs electrochemistry. ${ }^{15}$ In this method, graphite is employed as the anode in an electrochemical cell with a suitable counter electrode and electrolyte (typically ionic liquids, ${ }^{16}$ inorganic salts, ${ }^{15,17-19}$ or inorganic acids). ${ }^{15,20-25}$ Upon the application of a suitable potential, the graphite is electrochemically intercalated and oxidized. After removal from the reactor, the product is typically washed and exfoliated, usually with sonication, to single- or few-layered GO. One limitation of the current electrochemical GO (EGO) synthesis approaches is that they require graphite to be processed before it can be placed in the electrochemical reactor. In the vast majority of cases, a graphite electrode (in the form of rod or foil) is immersed in an electrolyte with a counter electrode parallel to it (see a review of the EGO studies in Table S2). For example, recent reports show that EGO can be produced within minutes by first oxidizing graphite foil in concentrated sulfuric acid and then exfoliating it at a high positive voltage in a dilute acid ${ }^{20}$ or inorganic salt electrolyte. ${ }^{17}$ However, graphite foil itself is a heavily processed material, requiring the raw graphite to first be acid-intercalated in the presence of strong oxidants, washed, dried, thermally expanded at $700{ }^{\circ} \mathrm{C}$ or more, and pressed into a foil (a flow diagram of this process is given in Figure S1). Accordingly, it can cost orders of magnitude more than its natural graphite precursor (a cost comparison appears in Table S1). To address this, we have previously reported a mechanically assisted production of EGO directly from loose graphite flakes, but that approach had a limited yield of $\sim 37 \%$ with respect to the starting graphite. ${ }^{26}$

A second limitation/unanswered question surrounding the electrochemical approaches is their scalability. In past reports, the diameter of the starting graphite rod or thickness of the foil is usually held constant at a small scale without upscaling. ${ }^{17,20,27}$ However, it cannot be assumed that the reaction outcome will be the same when the critical dimension of the electrode is changed. In order to overcome limitations of the existing EGO methods, we draw inspiration from additive manufacturing and the chemical reactionware approach. ${ }^{28}$ 
Herein, we take advantage of the rapid prototyping available with fused deposition modeling (FDM)-based 3D printing to examine new reactor designs for EGO synthesis directly from flake graphite. Motivated by previous work using packed-bed electrochemical reactors (PBERs) to anodically produce graphite intercalation compounds (GICs), ${ }^{29,30}$ we show that the PBER is also effective for GO synthesis. Using 3D printing, we are able to demonstrate the scalability of these reactors to the limits of the desktop 3D printer.

In the PBER, a bed of graphite flakes is pressed against a conducting substrate; we show that a conductive boron-doped diamond (BDD) is the singular choice for the substrate material. This can be attributed to BDD's unique advantages for aqueous electrochemistry (e.g., chemical robustness and very high overpotential for oxygen evolution). ${ }^{31-33}$ Extensive materials characterization of the product showed that reasonably well-oxidized EGO (19.7\% oxygen) with very good reaction yield $(155 \%$ with respect to the starting graphite) can be obtained. From a fundamental standpoint, we showed that the EGO is formed from a higher-stage GIC and how the electrochemical oxidation front propagates through the packed bed. We examined how the structure of GO can be tuned and its conductivity improved with a brief and mild heat treatment $\left(200{ }^{\circ} \mathrm{C}\right)$ in air. The good conductivity of thermally converted EGO makes it useful as a conductive filler in lithium-ion battery (LIB) cathodes.

\section{RESULTS AND DISCUSSION}

Development, Optimization, and Scalability of the Packed-Bed Reactor Model. In order to achieve scalable production of GO using flake graphite, a new PBER was designed, as illustrated in Figure 1A (photograph in Figure S2). The reactor consists of a glass tube of $14 \mathrm{~mm}$ interior diameter pressed and sealed against a BDD-coated niobium plate. A bed of flake graphite is in contact with the BDD and is separated from a platinum $(\mathrm{Pt})$ counter electrode with a glass fiber membrane. Good electrical contact between the graphite and BDD is ensured by pressing the packed bed down with a weighted plastic piece.

Initially, $40 \mathrm{mg}$ of flake graphite was oxidized in this way in 11.6 M sulfuric acid with a constant current of $16 \mathrm{~mA}(10.4$ $\mathrm{mA} / \mathrm{cm}^{2}$, based on the surface area of the top of the graphite packed bed) in a two-electrode configuration. The galvanostatic charging curve (Figure 1E) is similar to those previously reported for the anodic galvanostatic charging of bulk graphite particles in mineral acids. ${ }^{21,24,29,34-38}$ The reactor walls were constructed from glass to allow us to visually monitor the reaction, and we observed the graphite bed expanding throughout the entire process to several times its initial volume (Figure S3). Finally, as the quantity of unreacted graphite diminished, the voltage increased, and the predominant reaction shifted to the anodic oxygen evolution reaction [Figure 1E(iii)], as previously described. ${ }^{30,34,41,46-52}$ Indeed, when the voltage reached its final plateau, we observed gas bubbles continually leaving the sides of the graphite bed. At the end of the reaction, the product was immersed in water, yielding the fluffy graphite oxide product shown in Figure 1D.

Optimization of the Electrolyte and Current. Before the final reaction conditions were reached, several parameters were examined and optimized. X-ray diffraction (XRD) was used as the first tool to assess the product because it can probe the bulk material and provide a qualitative estimate of its constituents. The XRD patterns (Figure 2) typically exhibit
A

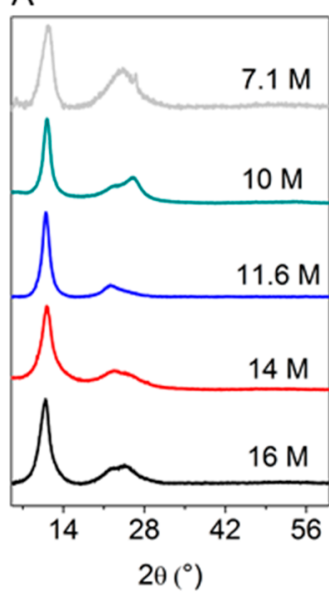

C

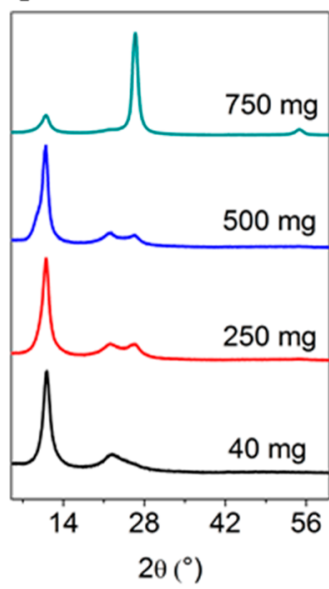

B

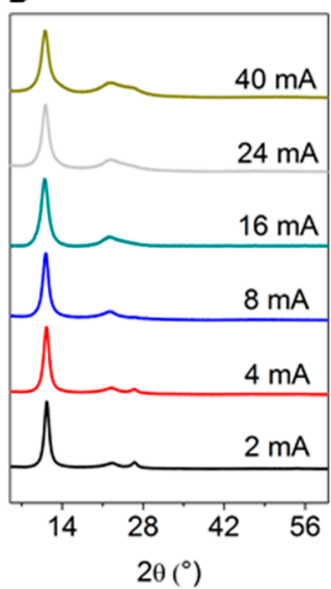

D

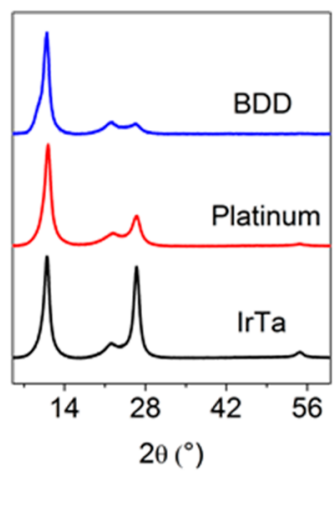

Figure 2. XRD diffractograms of the GO product resulting from oxidation with (A) different electrolyte sulfuric acid concentrations (constants: $40 \mathrm{mg}$ of starting graphite, $16 \mathrm{~mA}$ current), (B) different constant current values applied during the reaction (constants: $40 \mathrm{mg}$ of starting graphite, $11.6 \mathrm{M} \mathrm{H}_{2} \mathrm{SO}_{4}$ electrolyte), (C) different starting graphite amounts (constants: $24 \mathrm{~mA}\left(15.59 \mathrm{~mA} / \mathrm{cm}^{2}\right)$ current, 11.6 $\mathrm{M} \mathrm{H}_{2} \mathrm{SO}_{4}$ electrolyte), or (D) three different working electrode substrates, $\mathrm{BDD}, \mathrm{Pt}$, or IrTa (constants: $500 \mathrm{mg}$ of starting graphite, $24 \mathrm{~mA}, 11.6 \mathrm{M} \mathrm{H}_{2} \mathrm{SO}_{4}$ ). All diffractograms have been normalized to the maximum intensity, and vertical axis units are arbitrary.

two peaks characteristic of GO at roughly $11^{\circ}$ and $22.2^{\circ}$, similar to the previously reported patterns for EGO produced using sulfuric acid. ${ }^{17,25}$ The peak at around $11^{\circ}$ arises from the well-oxidized GO and represents the interlayer spacing between GO sheets ( $8.04 \AA)$, and the broad peak at roughly $22^{\circ}$ arises from the less oxidized regions of the GO. ${ }^{39,40}$

To optimize the process, the electrolyte concentration was first varied between $7.1 \mathrm{M}$ (50 wt \% sulfuric acid) and $16 \mathrm{M}$. The galvanostatic charging curves for these experiments are given in Figure S4. As is evident in Figure 2A, when the sulfuric acid concentration was $11.6 \mathrm{M}$, the XRD pattern showed a prominent GO peak $\left(\sim 11^{\circ}\right)$ with a very small proportion of less oxidized content $\left(\sim 22-30^{\circ}\right)$. However, either increasing or decreasing the acid concentration led to an increase in the area of the $\sim 22-30^{\circ}$ peaks relative to the $\sim 11^{\circ}$ GO peak. To provide a correlational measure of the GO content, the $11^{\circ}$ GO peak area was expressed as a ratio relative to the area under the peaks associated with the less oxidized forms of graphite around $\sim 22-30^{\circ}$ (as shown in Table 1 and illustrated further in Figure S5). Our results suggest that there is an 
Table 1. XRD Statistics and Mass Yield for All Optimization Reactions in the Smaller Setup

\begin{tabular}{|c|c|c|c|c|}
\hline & variable & $\begin{array}{c}\text { mass of product versus mass of starting } \\
\text { graphite }(\%)\end{array}$ & $\begin{array}{l}\mathrm{GO} / \text { less oxidized peaks } \\
\text { area ratio }\end{array}$ & $\begin{array}{l}\text { fwhm of the GO peak } \\
(2 \theta, \text { deg })\end{array}$ \\
\hline \multirow[t]{5}{*}{ acid concentration (constants: $40 \mathrm{mg}, 16 \mathrm{~mA}$ ) } & $7.1 \mathrm{M}$ & 143 & 0.95 & 2.147 \\
\hline & $10 \mathrm{M}$ & 155 & 1.20 & 1.404 \\
\hline & $11.6 \mathrm{M}$ & 164 & 3.40 & 1.442 \\
\hline & $14 \mathrm{M}$ & 157 & 2.36 & 1.991 \\
\hline & $16 \mathrm{M}$ & 98 & 1.82 & 1.888 \\
\hline \multirow[t]{6}{*}{ current (constants: $40 \mathrm{mg}, 11.6 \mathrm{M} \mathrm{H}_{2} \mathrm{SO}_{4}$ ) } & $2 \mathrm{~mA}$ & 170 & 3.99 & 0.986 \\
\hline & $4 \mathrm{~mA}$ & 161 & 4.49 & 1.102 \\
\hline & $8 \mathrm{~mA}$ & 160 & 4.32 & 1.151 \\
\hline & $16 \mathrm{~mA}$ & 164 & 3.40 & 1.442 \\
\hline & $24 \mathrm{~mA}$ & 174 & 2.90 & 1.364 \\
\hline & $40 \mathrm{~mA}$ & 164 & 2.12 & 1.491 \\
\hline \multirow[t]{4}{*}{ graphite loading (constants: $24 \mathrm{~mA}, 11.6 \mathrm{M} \mathrm{H}_{2} \mathrm{SO}_{4}$ ) } & $40 \mathrm{mg}$ & 174 & 2.90 & 1.364 \\
\hline & $250 \mathrm{mg}$ & 163 & 2.37 & 1.318 \\
\hline & $500 \mathrm{mg}$ & 162 & 2.92 & 1.217 \\
\hline & $750 \mathrm{mg}$ & 137 & 0.22 & 1.613 \\
\hline \multirow{3}{*}{$\begin{array}{l}\text { working electrode substrate (constants: } 500 \mathrm{mg}, 24 \mathrm{~mA} \text {, } \\
11.6 \mathrm{M} \mathrm{H}_{2} \mathrm{SO}_{4} \text { ) }\end{array}$} & $\mathrm{IrTa}$ & 143 & 0.88 & 1.184 \\
\hline & $\mathrm{Pt}$ & 143 & 1.73 & 1.283 \\
\hline & $\mathrm{BDD}$ & 162 & 2.92 & 1.217 \\
\hline
\end{tabular}

optimum balance for oxidation between the amount of acid versus the amount of water in the electrolyte, as previously demonstrated. ${ }^{21,34,37}$ The film conductivity measurements also clearly show that $11.6 \mathrm{M}$ acid led to the most insulating product, consistent with a higher degree of oxidation (Figure S4C). The $11.6 \mathrm{M}$ acid was thus selected for further experiments to maximize the extent of oxidation of the product (see Supplementary Note 1 for further rationale).

Having selected the acid concentration, the current was then optimized. XRD results for these experiments are shown in Figure $2 \mathrm{~B}$, and the charging curves, mass gain, and film conductivity are plotted in Figure S6. It is apparent that the time to reach the final voltage plateau was roughly proportional to the applied current, consistent with previous work. ${ }^{34}$ In terms of the product composition, XRD suggests that there is an optimal range for the applied current between 8 and $24 \mathrm{~mA}$. When the current is much greater than $24 \mathrm{~mA}$ or below $8 \mathrm{~mA}$, a more pronounced peak around $26^{\circ}$ emerges. This peak can be attributed to graphite with a very limited or residual degree of oxidation. ${ }^{41}$ In order to maximize the reaction rate without overly compromising the product quality, $24 \mathrm{~mA}$ (a current density of $15.6 \mathrm{~mA} / \mathrm{cm}$ ) was used for further experiments.

Effect of the Graphite Loading. To test the effect of the graphite loading, the reaction was scaled from $40 \mathrm{mg}$ of starting graphite to $500 \mathrm{mg}$, and the charging curves, yield, and film conductivity were measured (Figure S7). The charging curves are structurally similar with changes in the loading; however, when the starting mass was $250 \mathrm{mg}$ or more, the voltage did not reach a low voltage plateau at the end of the experiment. Instead, it developed a near-vertical slope, after which the reaction was stopped before the limit of the potentiostat was reached. This final rise in the voltage was a result of decreasing moisture content in the thick product bed toward the end of the reaction, evident upon visual inspection of the bed after it was removed from the reactor.

XRD (Figure 2C) shows that increasing the starting graphite to $750 \mathrm{mg}$ led to the graphitic peak becoming dominant, suggesting that graphite oxidation did not proceed to completion (a conclusion supported by the charging curves and mass yield, as explained in Supplementary Note 2). This reduced conversion to EGO is likely related to hindered electrolyte diffusion through the packed bed with increased starting graphite amount. This conclusion is supported by Raman spectra acquired from different locations in the bed at the end of the reaction, showing that the bottom of the bed is a pure graphite intercalation compound and the top and middle is rich in the graphite oxide product (Figure S8). In order to maximize the amount of product produced without significantly affecting the product quality, a $500 \mathrm{mg}$ scale (i.e., 0.3249 $\mathrm{g} / \mathrm{cm}^{2}$ ) was chosen for further study. Further reactor engineering could be carried out to increase the vertical limit by implementing strategies available in the reactor engineering literature for increasing electrolyte/ionic diffusion throughout packed beds. $^{42}$

Effect of the Working Electrode Substrate. The importance of the working electrode substrate material (up to this point, BDD) was also examined (Figure 2D). The BDD electrode was substituted with either $\mathrm{Pt}$ or an iridiumtantalum (IrTa) mixed metal oxide (MMO) anode material with low overpotential for oxygen evolution. Indeed, linear sweep voltammetry in the experimental electrolyte showed that IrTa was the most active material, followed by $\mathrm{Pt}$ and then BDD (Figure S9). Using the more active materials in place of $\mathrm{BDD}$ led to a reduction of the total reaction time before the slope of the voltage became nearly vertical (Figure S10). It also led to a significant increase in the proportion of graphite with a limited amount of oxidation, as is evident in the very intense XRD peak around $26.46^{\circ}$ for IrTa (Figure 2D). When IrTa is used, bubbles could be seen emerging from the graphite bed every few seconds throughout the experiment, even during the graphite overoxidation period. This oxygen evolution can lead to bubbles building up inside the bed, choking off the electrolyte, and increasing the voltage. Indeed, the IrTa charging curve (Figure S10) became unstable near the end of the reaction because of vigorous bubbling. Hence, the BDD electrode is a key component in the PBER that helps to limit bubble formation at the critical electrode/graphite physical and electrical interface.

Lateral Scalability. Ultimately, the aim of the current work is to enable the production of reactors that can mass-produce 
A

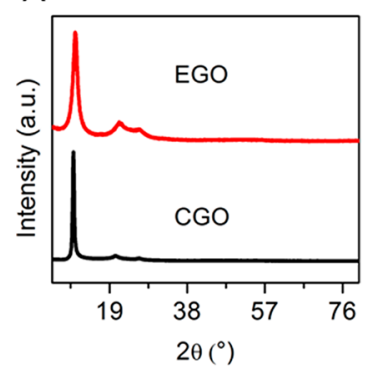

D

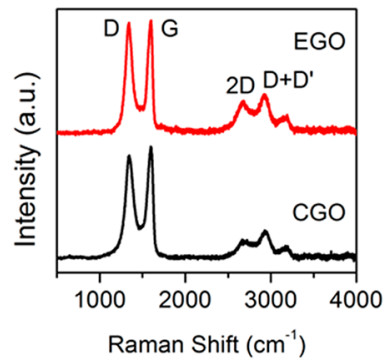

B

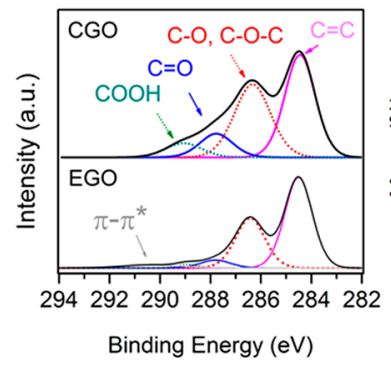

E

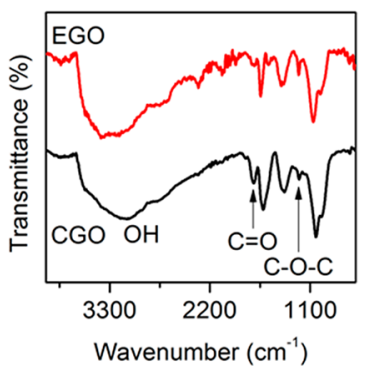

C

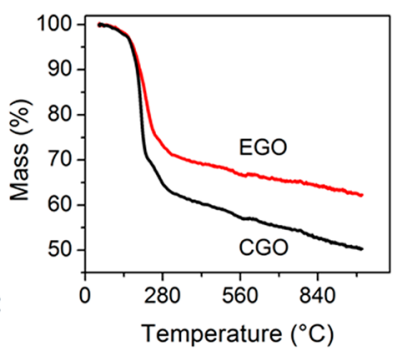

F

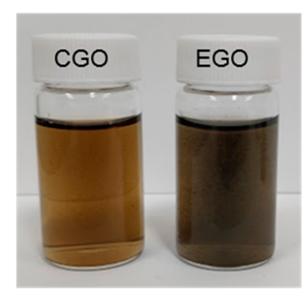

Figure 3. Material properties of exfoliated EGO compared with CGO. (A) XRD diffractograms. (B) High-resolution XPS C 1s spectra with deconvolution to show the contributions of oxygen functional groups. CGO has a greater degree of oxidation and accompanying functional groups. (C) FTIR spectra. (D) TGA curves measured in argon with a $10{ }^{\circ} \mathrm{C} / \mathrm{min}$ heating rate. (E) Raman spectra measured on vacuum-filtered membranes. (F) GOs dispersed in water by sonication at a concentration of $0.1 \mathrm{mg} / \mathrm{mL}$, with the $\mathrm{pH}$ adjusted to 10 with ammonia.

graphite oxide. To this end, a laterally scaled version of the reactor (Figures $1 \mathrm{~A}$ and $\mathrm{S} 11$ ) was produced using the commercially available FDM 3D printer. Materials used for this larger reactor were identical with those used for the smaller reactor, except that the walls were constructed from polypropylene (PP) instead of glass. The surface area of the working electrode (measured at the bottom of the bed) was increased 7.89 times from 1.539 to $12.15 \mathrm{~cm}^{2}$. The graphite loading per unit surface area was kept constant at $0.3249 \mathrm{~g} /$ $\mathrm{cm}^{2}$, leading to a starting graphite amount of $\sim 3.95 \mathrm{~g}$. The absolute current was scaled proportionally with the surface area.

After the reaction was run in this new setup, the total weight of the product was $6.1 \mathrm{~g}$, implying a mass increase of approximately $55 \%$ from the starting material. Laterally scaling the reactor in this way did not appear to affect the process or product of the reaction significantly. A comparison of the XRD diffractograms, X-ray photoelectron spectroscopy (XPS) C 1s spectra, charging curves, and mass recovered (normalized to the starting graphite) shows that the products of the smaller and larger reactors are very similar (Figure S12), confirming that the reactor can be scaled in the $X$ and $Y$ planes. The reaction and purification took roughly 1 day, $8 \mathrm{~h}$ (Table S3), requiring less time and far fewer steps than a typical modified Hummers method (Table S4).

Material Characterization. From the larger-scale reactor, the $6.1 \mathrm{~g}$ product cake was washed and briefly sonicated, then characterized and compared to CGO prepared from a modified Hummers method (Figure 3A-F). The XRD, XPS, and Raman data for the precursor graphite used for EGO synthesis are reported in Figure S13.

Chemical and Spectroscopic Characterization. Although EGO is broadly similar to its chemically produced counterpart, it differs in several ways. First, when dispersed in water, ethanol, or other organic solvent, EGO has a much darker brown appearance relative to CGO suspended at the same concentration (Figure $3 \mathrm{~F}$ ), suggesting a more conjugated graphitic structure. ${ }^{43}$ Regarding the XRD data (Figure $3 \mathrm{~A}$ ), both EGO and CGO have similar peaks, although the intensities of the $20-25^{\circ}$ peaks are higher for EGO. These peaks are associated with less oxidized materials, including exfoliated graphene or graphite with residual oxygen functional groups. $^{41}$

Deconvolution of the XPS C 1s spectra (Figure 3B and Table S7) reveals the presence of several components: $\mathrm{C}=\mathrm{C}$ carbon $(284.5 \mathrm{eV})$, carbon with hydroxyl or epoxy group (C$\mathrm{OH} / \mathrm{C}-\mathrm{O}-\mathrm{C}$ at around $286.3 \mathrm{eV})$, carbonyl carbon $(\mathrm{C}=\mathrm{O}$, $\sim 287.8 \mathrm{eV})$, and carboxyl carbon $(\mathrm{COOH}, \sim 289.0 \mathrm{eV})$. Hydroxyl and epoxy-bound carbon dominate the spectra, consistent with the previous results for GO. ${ }^{44} \mathrm{CGO}$ is clearly more oxidized, with a greater fraction of $\mathrm{C}=\mathrm{O}(11.4$ atom \%) and $\mathrm{COOH}(6.2 \%)$ groups relative to $\mathrm{EGO}$ (which only contains $5.5 \% \mathrm{C}=\mathrm{O}$ and $1.8 \% \mathrm{COOH}$ ). In addition, the EGO spectrum contains the $\pi-\pi^{*}$ satellite shoulder, indicative of the larger conjugated network. The survey spectra (Figure S14) suggest a C/O ratio of 3.00 for CGO ( $25.0 \%$ oxygen) and 4.07 for EGO ( 19.7\% oxygen). Thermogravimetric analysis (TGA; Figure 3C) confirms that EGO is less oxidized than CGO. Upon heating at $10{ }^{\circ} \mathrm{C} / \mathrm{min}$ in argon, there is a slight loss of mass in the materials before $150{ }^{\circ} \mathrm{C}$ because of water loss. After around $150{ }^{\circ} \mathrm{C}$, mass is precipitously lost, primarily because of the loss of oxygen functional groups and carbon in the form of gaseous $\mathrm{CO}$ and $\mathrm{CO}_{2}$.

The Raman spectra for EGO and CGO (Figure 3D) both exhibit the $\mathrm{D}$ band around $1340 \mathrm{~cm}^{-1}$, the $\mathrm{G}$ band around $1589 \mathrm{~cm}^{-1}$, and broad $2 \mathrm{D}$ and $\mathrm{D}+\mathrm{G}$ bands around 2500$3300 \mathrm{~cm}^{-1}$, characteristic of oxidized graphite. ${ }^{45,46}$ Relative to pure graphite, the defect-activated D band intensifies in EGO, as defects from $\mathrm{sp}^{3}$ carbon and hole vacancies are introduced to the carbon lattice. There are several differences between the Raman spectra of EGO and CGO. First, the full width at halfmaximum (fwhm) for CGO is slightly wider than that for EGO 
(the fwhm values for a two-component fitting are shown in Table S5), a feature that is in some cases observed with more defective GO. ${ }^{47}$ This is consistent with the XPS data, which showed fewer $\mathrm{COOH}$ groups in EGO than CGO (n.b. the $\mathrm{COOH}$ groups are typically associated with edges and defects). Second, there is a more intense interband region between the $\mathrm{G}$ and $\mathrm{D}$ peaks for CGO. This can be attributed to an additional component, the $\mathrm{D}^{\prime \prime}$ (also known as D3 $)^{48-50}$ peak. Fitting the spectra with four components ${ }^{51}$ reveals that CGO has a more intense and wider $\mathrm{D}^{\prime \prime}$ band (fitting in Figure S16 and Table S6). The $\mathrm{D}^{\prime \prime}$ band has been correlated to more amorphous carbon structures. Finally, the ratio of the intensities of the fitted $\mathrm{D}$ and $\mathrm{G}$ bands $\left(I_{\mathrm{D}} / I_{\mathrm{G}}\right.$ ratio) for CGO (1.27) is somewhat greater than that for EGO (1.18). Claramunt et al. ${ }^{51}$ have shown that the fitted $I_{\mathrm{D}} / I_{\mathrm{G}}$ ratio is directly proportional to the $\mathrm{sp}^{2}$ carbon fraction. This suggests that EGO has relatively more $\mathrm{sp}^{2}$ carbon, consistent with the XPS data.

Fourier transform infrared (FTIR; Figure 3E) spectra confirm the presence of oxygen functional groups in both EGO and CGO. The curves are qualitatively similar, containing an $\mathrm{O}-\mathrm{H}$ stretching absorbance in the $3700-2400 \mathrm{~cm}^{-1}$ region and an absorbance peak around $1723 \mathrm{~cm}^{-1}$, which can be assigned to carbonyl-containing groups such as carboxylic acids. $^{52}$ The fingerprint region, around $500-1500 \mathrm{~cm}^{-1}$, is a region of spectral overlap where it is difficult to assign peaks. ${ }^{52}$ However, the subtle peak at $1222 \mathrm{~cm}^{-1}$ has been ascribed to the asymmetric stretching of the epoxide functional group. ${ }^{53}$ The remaining peaks, including the peaks around 1388 and $1043 \mathrm{~cm}^{-1}$, are formed from mostly $\mathrm{C}-\mathrm{O}$ and $\mathrm{C}=\mathrm{O}$ contributions. ${ }^{53}$

Morphological Characterization. In order to assess its morphological characteristics, EGO was dispersed in dimethylformamide (DMF) and spin-coated onto a $\mathrm{Si} / \mathrm{SiO}_{2}$ wafer for scanning electron microscopy (SEM) and atomic force microscopy (AFM) characterization or drop-casted onto a holey carbon grid for transmission electron microscopy (TEM) imaging. SEM (Figures 4D and S15B,C) and TEM (Figure S15D) images reveal that the sheets have a typical GO morphology. Particle size analysis of multiple SEM images revealed an average lateral size of $2.15 \mu \mathrm{m}$ (Figure 4B). AFM revealed that the majority of the graphene was exfoliated to a single layer, typically $1-1.2 \mathrm{~nm}$ thick, consistent with literature reports for CGO and EGO (Figures 4A,C and S13A). ${ }^{17,20,26}$

Mechanism of EGO Formation in the PBER. In order to better understand the mechanism of EGO formation in the PBER, the reaction in the tubular glass reactor was stopped approximately halfway through (i.e., after $11 \mathrm{~h}$ instead of the full $22.5 \mathrm{~h}$ ). The bottom of the EGO cake (roughly $2-3 \mathrm{~mm}$ ) had a distinct silver color when it was illuminated with a flashlight compared to the black upper part of the cake, as shown in Figure 5A. It is noteworthy that if the reaction is run to completion, the reactant cake is thicker and uniformly black (Figure 5B). Approximately $1 \mathrm{~mm}$ of the bottom of the cake (i.e., the part closest to the BDD electrode) and the top half of the cake were cut off and characterized separately. The material was characterized in the experimental electrolyte within $1 \mathrm{~h}$ of removal from the reactor to prevent the reaction products from decomposing over time. The top component's XRD and Raman results resemble those of GO, while the bottom component's results resemble those of a GIC (Figure $5 \mathrm{C}-\mathrm{J})$.

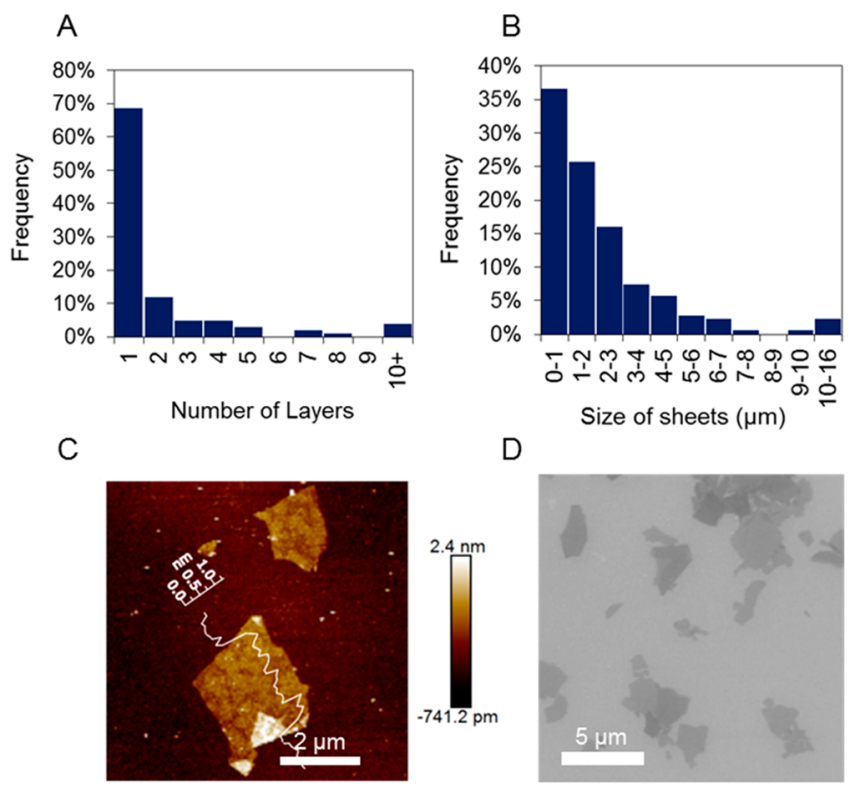

Figure 4. Morphological characteristics of the as-prepared EGO. (A) Layer distribution derived from AFM images. (B) Flake size distribution derived from SEM images. (C) AFM line profile of a typical single-layer EGO sheet with a height of approximately $1 \mathrm{~nm}$. (D) SEM image of several EGO sheets spin-coated onto a $\mathrm{Si} / \mathrm{SiO}_{2}$ wafer. Additional images are given in Figure S15.

Specifically, in the bottom, we can assign the Raman spectrum to that of a stage III-IV GIC. GICs are given stage assignments based on the average number of graphene layers between layers of intercalant, with stage $n$ indicating that there are $n$ graphene layers between adjacent layers of intercalant. The stage number can be determined from the Raman peaks at 1591 and $1617 \mathrm{~cm}^{-1}$, arising from the $E_{2 g}$ and $E_{2 g^{\prime}}$ modes, respectively. ${ }^{54,55}$ These modes are a result of vibrations of the graphite lattice, with $\mathrm{E}_{2 \mathrm{~g}^{\prime}}$ being associated with "boundary layer" graphite planes next to a layer of intercalant. ${ }^{54}$ In general, as the stage index decreases, the intensity of $E_{2 g}$ decreases and that of $\mathrm{E}_{2 \mathrm{~g}^{\prime}}$ increases. In our case, $\mathrm{E}_{2 \mathrm{~g}}$ is much less intense than $\mathrm{E}_{2 \mathrm{~g}^{\prime}}$, which has been observed for stage III and IV $\mathrm{H}_{2} \mathrm{SO}_{4}$-based GICs produced from anodic oxidation. ${ }^{17,55}$ $\mathrm{XRD}$ is consistent with this stage assignment. The (002) reflection is expected to be around $24.7^{\circ}$ for a stage III compound, $^{56}$ as previously observed experimentally ${ }^{17,41,56,57}$ (peak labeling of the bottoms XRD is given in Figure S18). The small shift of the (002) peak to $25^{\circ}$ found here is most likely due to the presence of the higher stage IV compound. In contrast, the GO (002) reflection is evident in the tops. Relative to the washed and dried product, this peak is shifted to a lower angle because of increased interlayer spacing from the intercalated water and acid. The Raman spectrum for the tops is similar to that of the final, purified whole product, with obvious $\mathrm{D}\left(1352 \mathrm{~cm}^{-1}\right)$ and $\mathrm{G}\left(1605 \mathrm{~cm}^{-1}\right)$ peaks. It differs from the final product in that $I_{\mathrm{D}} / I_{\mathrm{G}}$ is much lower $(0.78)$, the $D$ and $G$ peaks are slightly shifted, and the $G$ peak is bifurcated, with a sharp shoulder at $1627 \mathrm{~cm}^{-1}$.

Thoroughly water washing $\mathrm{GICs}^{41,58}$ or $\mathrm{GO}^{37,59}$ leads to their hydrolytic decomposition. The hydrolysis affects both EGO (the top product isolated here) and any remaining GIC (the bottom product). From XRD, it appears that water treatment causes the bottom GIC to deintercalate in order to form graphite with only limited residual oxygen functional 

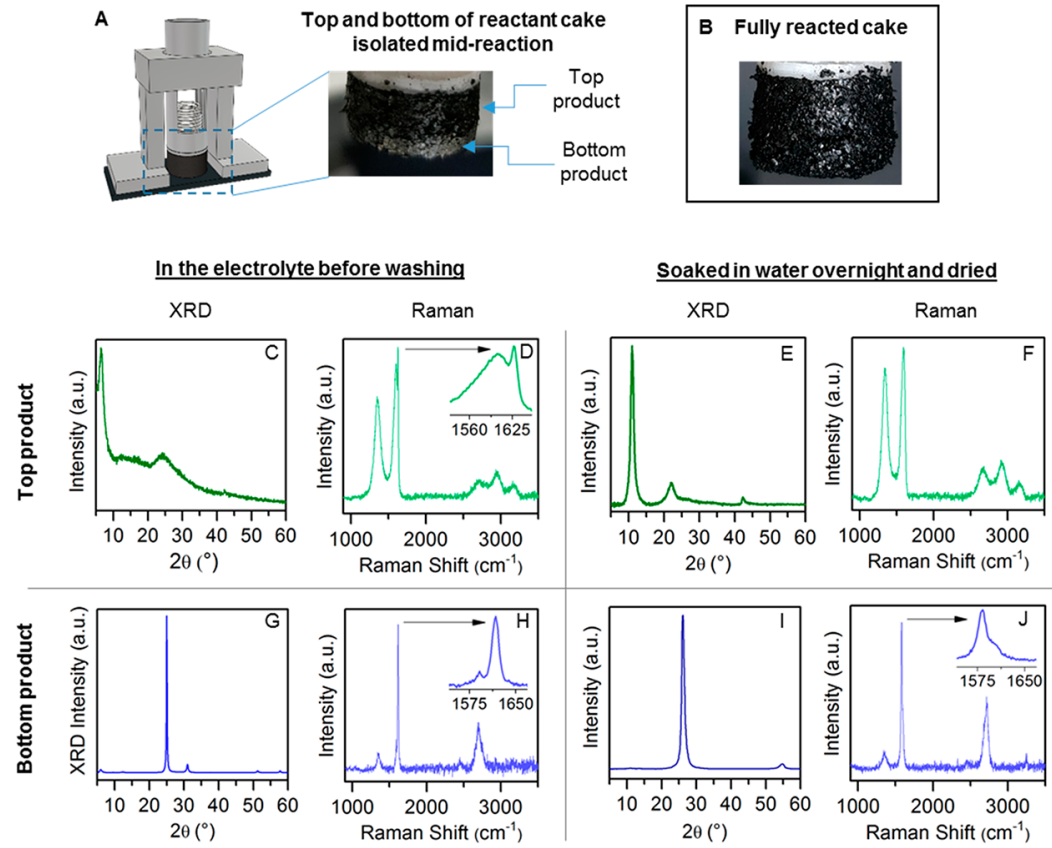

Figure 5. Characterization of the top and bottom parts of the partially reacted packed bed. Approximately halfway through the time required for a complete reaction, the reaction was stopped, and the cake was carefully removed from the apparatus. Two types of graphite were obvious upon visual inspection (A). The reactor cake from a separate experiment that was allowed to run to completion is shown for comparison (B). The top $(\mathrm{C}-\mathrm{F})$ and bottom $(\mathrm{G}-\mathrm{J})$ parts of the reactor cake were carefully separated and subjected to XRD and Raman spectroscopy both before (C-D and $\mathrm{G}-\mathrm{H})$ and after $(\mathrm{E}-\mathrm{F}$ and $\mathrm{I}-\mathrm{J})$ washing with water. The top product appears to be rich in EGO, while the bottom product is rich in a stage III-IV GIC.

groups. ${ }^{41}$ The top product, after drying, sees a shift in the (002) reflection to $11.00^{\circ}$ and the emergence of the $20.06^{\circ}$ and $42.33^{\circ}$ peaks. The $42.33^{\circ}$ peak arises from the (100) plane and is observed here because the $\mathrm{GO}$ at this point has not been exfoliated. After sonication, crystalline order along this plane is lost, and this peak is no longer observed (see Figure S20 for the postsonication $\mathrm{XRD}$ ). Thus, water washing plays an important role in the production of the final product, hydrolyzing any existing sulfates, ${ }^{52}$ removing sulfuric acid, and potentially reacting with and even creating oxygencontaining groups. ${ }^{58}$

As a control, the top product was not washed with water but rather was immersed in acetone overnight and then dried for 2 days. In this case, a distantly different pattern of peaks is observed with XRD, as shown in Figure S19. Washing the products of the Hummers method with organic solvents also produces unique types of graphite oxides because the organic solvents do not react with GO in the way water does. ${ }^{43,59}$ It is likely that there are analogous pre-water-treated products for EGO. On the basis of this evidence, we suggest the mechanism graphically summarized in Figure 1B, Figure S21 and explained further in Supplementary Note 3. On a macroscopic scale, we have observed that the electrochemical oxidation front proceeds from the top to the bottom of the packed bed, wherein the EGO product first forms at the top of the packed bed. This top-to-bottom reaction sequence is consistent with a previous report that found that electrochemical GIC-forming reactions in a packed bed also started near the bulk solution and proceeded downward. ${ }^{60}$

Thermal Postprocessing of EGO and CGO. Mild thermal annealing in air is an attractive strategy for deoxygenation of GO because it is scalable, economical, and does not introduce new chemicals into the material.
Furthermore, by limiting the heat transferred to the material, thermal treatment can be a simple way to tune the GO's oxygen functionalization. To achieve this, we heated GO samples for a fixed amount of time ( $5 \mathrm{~min}$ to $4 \mathrm{~h}$ ) at a relatively low temperature of $200{ }^{\circ} \mathrm{C}$. $200{ }^{\circ} \mathrm{C}$ is close to, but above, the threshold temperature required for significant mass loss in $\mathrm{GO}$, as demonstrated by previous studies in air on $\mathrm{EGO}^{15,17}$ and $\mathrm{CGO}^{61,62}$ and by a TGA conducted with our materials in a $20 \%$ oxygen atmosphere (Figure S22). With thermal treatment, the conductivity of both EGO and CGO tends to rise orders of magnitude and the mass significantly falls (Figure $6 \mathrm{~A}, \mathrm{~B}$ and Table S8). The improvement in the conductivity is due to the loss (or rearrangement) ${ }^{63-65}$ of oxygen functional groups and restoration of $\mathrm{sp}^{2}$ domains. Some of the oxygen is lost as molecular oxygen, but the reactions can also remove graphitic carbon (e.g., during the formation of $\mathrm{CO}$ or $\mathrm{CO}_{2}$ ). ${ }^{63}$

Importantly, we find that, at all time points, EGO has conductivity superior to that of CGO. At $1 \mathrm{~h}$, EGO's conductivity peaks at $17882 \mathrm{~S} / \mathrm{m}$, while CGO's conductivity is $877 \mathrm{~S} / \mathrm{m}$. As discussed above, as-prepared EGO has fewer oxygen functional groups than $\mathrm{CGO}$, giving it higher inherent conductivity. Larciprete et $\mathrm{al}^{63}$ suggested that thermally induced lattice damage (from $\mathrm{CO}$ and $\mathrm{CO}_{2}$ reactions) is catalyzed by a high surface density of epoxide species. The XPS data described above are consistent with CGO having more epoxide groups, potentially leaving it more susceptible to this type of lattice damage.

XRD shows that the predominate diffraction peak shifts during thermal treatment from $\sim 11^{\circ}$ to $24.8^{\circ}$ as oxygen groups are removed and the interlayer spacing contracts (Figure $6 \mathrm{C}$ ). The widening fwhm of the (002) reflection implies a decreased crystallite size, in part due to shrinking graphitic domains. Raman spectra (Figure S23) further show that increased 

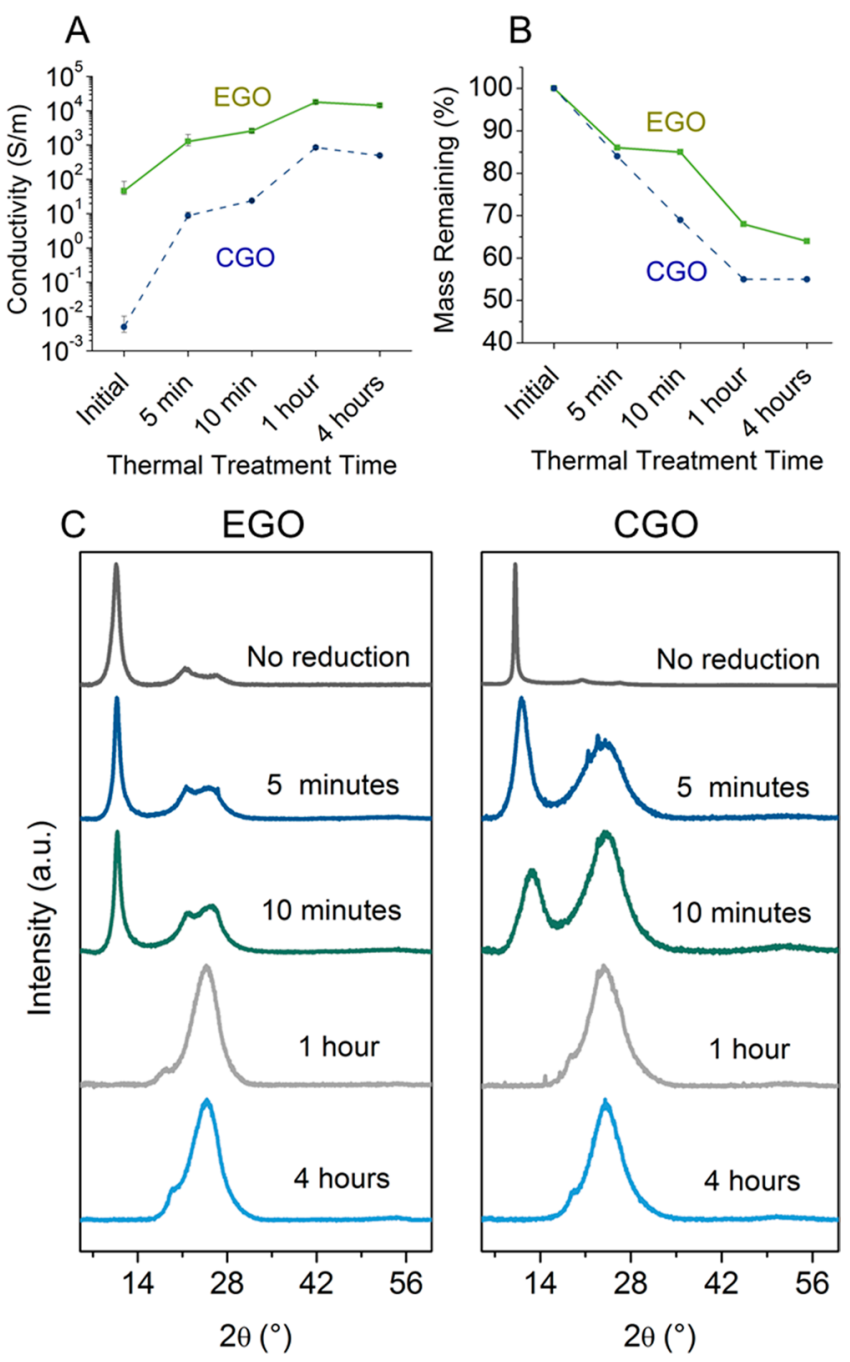

Figure 6. Thermal treatment of EGO versus CGO. (A) Mean conductivity of $\sim 20-\mu$ m-thick GO films after various treatment periods in a $200{ }^{\circ} \mathrm{C}$ oven in air. The conductivity of each film was measured multiple times, and error bars represent the interquartile range. (B) Mass lost during the thermal treatment. The interquartile range of repeated mass measurements on each film was less than $2 \%$. (C) Evolution of the XRD diffractograms during the thermal treatment.

oxidation time led also to a qualitative increase in the $\mathrm{D} / \mathrm{G}$ interband intensity, likely due to an increase in the $\mathrm{D}^{\prime \prime}$ mode associated with amorphitization. ${ }^{51}$ FTIR shows that, chemically, the changes in EGO are not identical with those in CGO (Figure S24). Although both EGO and CGO quickly lose hydroxyl and epoxy functional groups, by the end of the thermal treatment, CGO continues to show a sharp peak for $\mathrm{C}=\mathrm{O}$ moieties, while EGO does not. Differences in the initial extent of oxidation and structure likely account for the differences in the transient and final products.

Application in LIBs. $\mathrm{rGO}^{66,67}$ and electrochemically exfoliated graphene ${ }^{68,69}$ have proven to be useful as conductive fillers in LIB cathodes. Graphene can improve the charge transport through the cathode and also itself participate in lithium redox reactions. ${ }^{68}$ We thus tested the effect of adding our EGO or the previously characterized CGO into lithiumiron phosphate (LFP) cathodes for LIBs. The cathodes were based on a model coin cell setup (Figure S25) using $10 \mathrm{wt} \%$ poly(vinylpyrrolidone) (PVP) as the binder and 10 wt \% carbon black ( $\mathrm{CB}$ ) as the conductive filler. To evaluate the efficacy of GO addition without further optimization, $50 \%$ of the $\mathrm{CB}$ was replaced with $\mathrm{GO}$, and the dried cathode was subjected to thermal annealing at $200{ }^{\circ} \mathrm{C}$ for $10 \mathrm{~min}$. As shown in Figure $7 \mathrm{~A}$, at all charging rates, the LIB with EGO had a higher specific capacity relative to the battery without GO. The performance was improved over CGO at higher charging rates. The charge/discharge curves in Figure $7 \mathrm{~B}$ show a typical trend where the voltage plateaued as active sites in the LFP particles reacted with lithium ions, a plateau that is higher at higher charging rates. SEM images (Figure 7C,D) show the EGO clearly wrapping around single LFP particles and/or spreading across multiple particles. The conformal, wrapped morphology is similar to previously reported LIB cathodes with electrochemically exfoliated graphene. ${ }^{68}$ We might expect that our EGO enhances LIBs in a manner similar to that in previous work, i.e., because of superior charge transfer throughout the cathode due to the conductive nature of thermally converted EGO.

\section{SUMMARY AND CONCLUSIONS}

In this paper, we have presented a scalable approach to synthesizing EGO from flake graphite with high current efficiency and yield. By forming GICs in the same reactor as that used for oxygen functionalization, we obviate the need for preintercalation and eliminate multiple, costly steps required when using graphite rods or foil (Figure S1). Further, by using flake graphite as opposed to more processed graphite, we have reduced the price of the cost-controlling graphite input by an order of magnitude (Table S1). The use of BDD allows us to maintain specificity for graphite oxidation, and by operating at low current, we further minimize unwanted water splitting in the packed bed. Relative to CGO, our EGO is better able to maintain the conductivity of graphite, conductivity that can be tunably enhanced with a mild $200{ }^{\circ} \mathrm{C}$ treatment. Combined with EGO's solution processability, this opens up the possibility of solution mixing EGO into composite structures, followed by thermal defunctionalization, a strategy we demonstrated with LIB cathodes. In addition to energy storage devices, the favorable conductivity of EGO makes it a candidate for other electronic applications, such as sensors and flexible/wearable devices. In terms of the mechanism of the reaction, we elucidate how the reaction proceeds through the bed from top to bottom, transforming graphite from a stage III-IV GIC to EGO. Our results highlight how reactor engineering via $3 \mathrm{D}$ printing and the selection of a niche $\mathrm{BDD}$ electrode can expand the possible synthetic routes for scalable and cost-effective electrochemical production of GO.

\section{EXPERIMENTAL SECTION}

The methods are described concisely below. Further notes on the reactor fabrication, EGO synthesis, and sample preparation for characterization can be found in the Supporting Information, Expanded experimental section.

Fabrication of Electrochemical Reactors. 3D-printed components for the reactors were designed in Autodesk 123D Design. For the smaller glass reactor, a conical weight platform and the flanges used to clamp the reactor to the BDD (or other working electrode) plate were printed using a semitransparent 1.75 -mm-diameter $\mathrm{ABS}$ filament (Verbatim Americas LLC, Charlotte, NC). The cylindrical graphite press was printed with a semitransparent 1.75 -mm-diameter poly(vinylidene difluoride) (PVDF) filament (Apium Additive Technologies, Karlsruhe, Germany). All parts for the larger PP reactor were printed using a semitransparent 1.75 -mm-diameter PP 

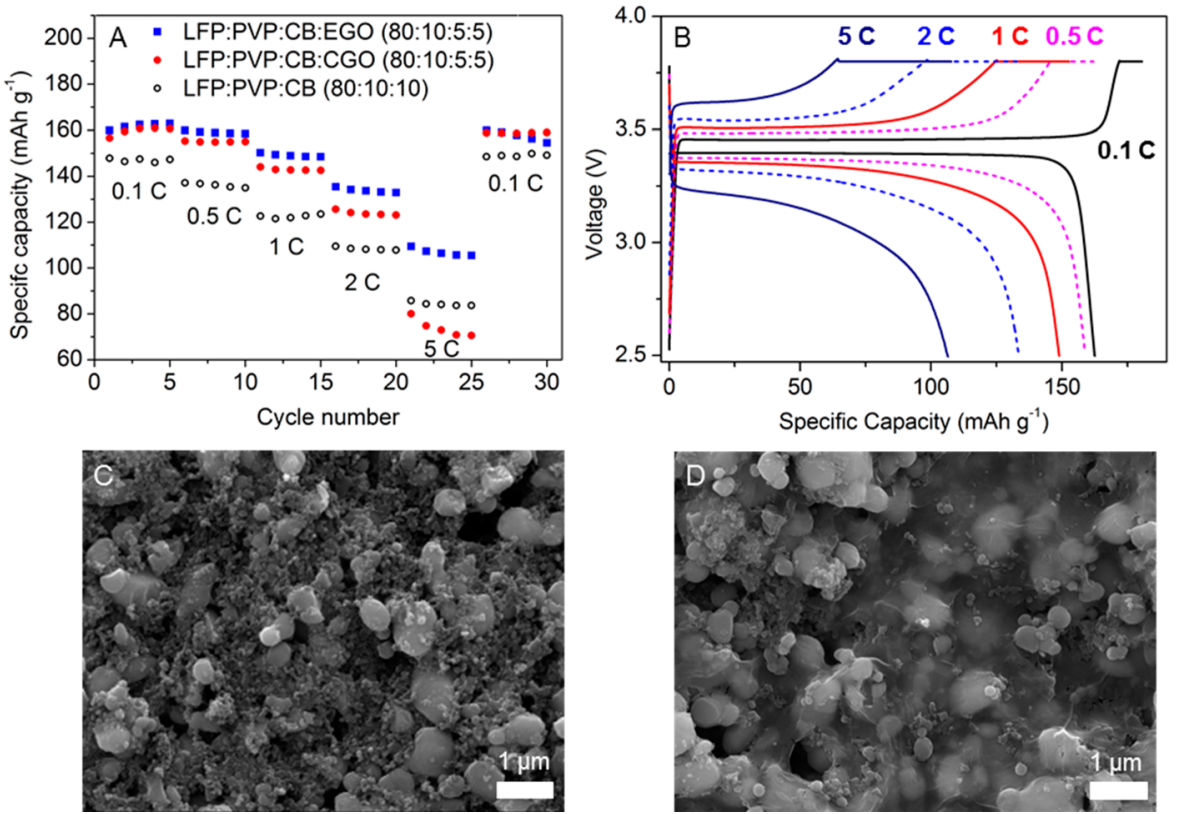

Figure 7. LIB characterization with and without GO addition. Experimental cathodes were made by mechanically mixing LFP, PVP, CB, and EGO or CGO in a 80:10:5:5 mass ratio. The GO cathodes were briefly heat-treated at $200{ }^{\circ} \mathrm{C}$ in air. As a control, cathodes were prepared in the conventional manner without GO. (A) Performance testing of the LIBs at five charging rates. (B) Charge/discharge profiles for the EGO cathode at different charging rates (data shown for the third cycle at each charging rate). (C) SEM image of the cathode material prepared without GO. (D) SEM image of the cathode with EGO. Large spherical particles of approximately $1 \mu \mathrm{m}$ are LFP, while smaller spherical particles are CB.

filament (Verbatim Americas LLC, Charlotte, NC). All parts were printed using a Makergear M2 or M3 3D printer (Beachwood, $\mathrm{OH}$ )

The smaller reactor was assembled by first gluing a $14 \mathrm{~mm}$ glass tube to the 3D-printed clamping flanges (Figure S26). The tube was then clamped onto the working electrode substrate (e.g., a BDD plate). Parafilm (Parafilm M, Bemis, Neenah, WI) with a 13-mmdiameter hole punched in was used to form a seal. The BDD plate was $100 \mathrm{~mm}$ (length) $\times 20 \mathrm{~mm}$ (width) $\times 2 \mathrm{~mm}$ (height) and was composed of niobium coated with chemical-vapor-deposition-grown polycrystalline BDD (Diaccon $\mathrm{GmBH}$, Fürth, Germany). The thickness of the BDD film was $12-18 \mu \mathrm{m}$. The Pt anode was a foil of $0.05 \mathrm{~mm}$ thickness (Item 690-996-10, Goodfellow, Cambridge, U.K.). The IrTa MMO was a $100 \times 100 \mathrm{~mm}$ titanium plate coated with the active anode material (Baoji Qixin Titanium Company, Ltd., Baoji City, China).

Three glass microfiber filters (pore size $0.7 \mu \mathrm{m}$, Whatman brand from GE Healthcare, Chicago, IL; Catalog No. 1825-047) were stacked on top of the graphite. A 3D-printed, weighted press with a porous bottom (Figures S27 and S28) was then placed on top of the glass fiber membranes to hold the graphite down. The counter electrode consisted of a $33 \mathrm{~cm}$ loop of $0.25-\mathrm{mm}$-diameter $\mathrm{Pt}$ wire (Item 850-988-64, Goodfellow, Cambridge, U.K.) suspended approximately $4 \mathrm{~mm}$ from the glass fiber membrane. The working and counter electrodes were connected to a Gamry Interface 1000 potentiostat (Gamry Instruments, Warminster, PA).

The larger rectangular PP reactor (schematic in Figure S11;3D models shown in Figures S26-S32) used the same BDD working electrode material. The counter electrode was a $186 \mathrm{~cm}$ Pt wire loop made of the same material as that used previously and was again suspended roughly $4 \mathrm{~mm}$ above the bottom of the graphite press. The porous graphite press was 3D-printed in PP. The glass fiber membrane was the same material as that used above, and the seal between the BDD and plastic was created using three pieces of Parafilm M. The weight platform was a rectangular plastic piece. The Gamry Interface 1000 was again used for these experiments.

Several iterations of the reactor were developed in our laboratory. Each reactor took less than 1 day to print and required less than $250 \mathrm{~g}$ of filament, highlighting the advantage of $3 \mathrm{D}$ printing for rapid prototyping.
Synthesis of EGO. Natural flake graphite (Sigma-Aldrich Product Number 332461; particle size, +100 mesh) was poured through the opening at the top of the reactors. The glass fiber membrane separators and the 3D-printed graphite press were then placed atop the bed of graphite. Weight was then added to the top of the graphite press (roughly $0.5 \mathrm{~kg}$ for the smaller reactor and $2.5 \mathrm{~kg}$ for the larger reactor). The $\mathrm{Pt}$ wire counter electrode was cleaned before each experiment by first sonicating in acetone for $3 \mathrm{~min}$ and rinsing in ethanol and deionized water; then, the counter electrode was electrochemically cleaned. This cleaning was done in a three-electrode cell in $0.5 \mathrm{M} \mathrm{H}_{2} \mathrm{SO}_{4}$ and consisted of a constant $+2 \mathrm{~V}$ for 2 min versus saturated calomel electrode (SCE), followed by cyclic voltammetry between -0.23 and $1.10 \mathrm{~V}$ versus SCE with a scan rate of $100 \mathrm{mV} / \mathrm{s}$ for 20 cycles, stopping at $1.1 \mathrm{~V}$.

The sulfuric acid electrolyte was diluted with deionized water from 98\% sulfuric acid purchased from ChemSupply (Gillman, SA, Australia). A total of $3.6 \mathrm{~mL}$ of electrolyte was used for the smaller setup, and $28.4 \mathrm{~mL}$ was used for the larger setup. Before the start of the reaction, the graphite press was manually agitated to remove any entrapped air bubbles from the graphite bed. The experiments were run in a constant-current, two-electrode configuration. After the experiment appeared to reach the final voltage plateau, it was allowed to continue to run until at least $60 \mathrm{C}$ of charge had been transferred from the graphite bed. This was to ensure that the final voltage plateau had, in fact, been reached and that the slope of the voltage curve had stabilized. When the graphite loading was $250 \mathrm{mg}$ or more, the voltage curve did not plateau below $12 \mathrm{~V}$ but rather began to rapidly rise at the end. In this case, the experiment was stopped when it was evident that the slope of the voltage curve was approaching vertical.

At the conclusion of the EGO synthesis, for the smaller setup, the EGO was transferred to $125 \mathrm{~mL}$ of deionized water. For the larger $\sim 4$-g-scale reactor, the product was first transferred into $\sim 100 \mathrm{~mL}$ of 50 wt \% sulfuric acid to avoid excessive heat from acid dilution. The acid was then filtered off, and the solids were transferred into $1 \mathrm{~L}$ of deionized water. The product was then stored at $4{ }^{\circ} \mathrm{C}$. The yield was found by pipetting up a known volume of the product solution, sonicating it for 5-10 min, forming a film via vacuum filtration, drying 
the film overnight in an $80{ }^{\circ} \mathrm{C}$ oven in air, and then quickly removing and weighing the freestanding film.

Synthesis of CGO. The synthesis procedure was based on a twostep modified Hummers method using acid-treated graphite as the precursor. $^{70}$ This graphite was sourced from Asbury Graphite Mills, grade 1721 , and was sieved to retain $200-300 \mu \mathrm{m}$ flakes. A total of 1 $\mathrm{g}$ of the graphite precursor was mixed with concentrated $\mathrm{H}_{2} \mathrm{SO}_{4}$ (50 $\mathrm{mL}$ ) in a $500 \mathrm{~mL}$ three-necked flask and placed in an ice bath with mechanical stirring at $120 \mathrm{rpm}$. After the temperature was cooled below $10{ }^{\circ} \mathrm{C}, \mathrm{KMnO}_{4}(3 \mathrm{~g})$ was slowly added to the mixture, and the mixture was kept in an ice bath for $1 \mathrm{~h}$. The ice bath was removed, and the reaction temperature was elevated to $45{ }^{\circ} \mathrm{C}$ and held at this temperature for $4 \mathrm{~h}$. After this reaction, the water bath was replaced with an ice bath, and $150 \mathrm{~mL}$ of cooled water was slowly added into the mixture via a peristaltic pump over a period of $90 \mathrm{~min}$. The reaction system was then kept in the ice bath for another $30 \mathrm{~min}$. At the end of the reaction, in order to react away residual $\mathrm{KMnO}_{4}, \mathrm{H}_{2} \mathrm{O}_{2}$ was added dropwise until the color of the resulting product stopped changing. To remove residual metal ions, $300 \mathrm{~mL}$ of a dilute $\mathrm{HCl}$ solution (1:9) was added to the product, and the product was allowed to sediment overnight. The resulting sediment was taken as the product and the supernatant discarded. The product was washed with water and centrifuged at $13000 \mathrm{rpm}$ for $15 \mathrm{~min}$ repeatedly until the $\mathrm{pH}$ of the supernatant stabilized at $\sim 4$. Finally, the product was suspended in $200 \mathrm{~mL}$ of deionized water and stored in a refrigerator at $4{ }^{\circ} \mathrm{C}$.

Sample Preparation and Materials Characterization. General characterization and purification procedures are described here. For additional details about the sample preparation for XRD, XPS, SEM, and AFM, see the Supporting Information, Expanded experimental section.

XRD was performed on a Bruker D8 Advance diffractometer, equipped with a graphite monochromator. Thin films were scanned in fixed sample illumination mode ( $5 \mathrm{~mm}$ illumination length), and packed-bed samples were scanned with a fixed divergence slit of $0.1^{\circ}$. For all samples, the scan rate was $3 \% \mathrm{~min}$. The spectra were background-corrected where necessary, and the area under the curves was calculated using Bruker Diffrac.Eva 4 software.

To purify the samples for further characterization, EGO was washed with several rounds of centrifugation. First, $500 \mathrm{mg}$ of the product was rinsed several times with deionized water in a vacuum filtration cup and then sonicated for $10 \mathrm{~min}$ in deionized water in order to expand the graphite. Subsequently, the product was centrifuge-washed four times at $4800 \mathrm{rpm}(2437 \mathrm{~g})$ for $30 \mathrm{~min}$ in a Velocity $18 \mathrm{R}$ centrifuge (Dynamica Scientific, Livingston, U.K.). CGO was not further purified beyond the centrifuge washing already described.

XPS data were acquired using a photon energy of $1486 \mathrm{eV}$ from the soft X-ray spectroscopy beamline at the Australian Synchrotron with a SPECS Phoibos 150 hemispheric analyzer. Binding energies of all XPS spectra were calibrated using a clean gold foil in electrical contact with the samples. SEM, AFM, and single-flake Raman analysis were performed on EGO spin-coated onto a conductive $\mathrm{Si} / \mathrm{SiO}_{2}$ wafer (for SEM and AFM) or a $300 \mathrm{~nm}$ wet thermal oxide silicon wafer (for single-flake Raman spectroscopy). SEM was conducted on a Joel JSM7500FA microscope. AFM images were collected using a Bruker Dimension Icon atomic force microscope with a RTESPA300 probe operating in ScanAsyst mode. ImageJ was used for particle-size analysis of the SEM images, and the size distribution was based on 175 flakes. AFM images were analyzed using Bruker Nanoscope Analysis. The height of 102 flakes was measured using the line profile tool.

Raman spectroscopy was performed on a Renishaw inVia Raman microscope equipped with a $532 \mathrm{~nm}$ laser and $20 \times$ and $100 \times$ objectives (used on the single-flake graphene). The spectra were background-corrected and curve-fit using Renishaw Wire 5.0 software. For most Raman analysis, measurements were acquired from a vacuum-filtered membrane created from an aqueous suspension of the purified product. For Raman analysis on the wet product taken directly from the reactor, the EGO was spread onto a glass slide. For this and all Raman testing, the spectra were randomly acquired from at least 10 different flakes (or parts of the membrane) to ensure that the presented spectra were representative. Attenuated-total-reflectance Fourier transform infrared (ATR-FTIR) spectra were acquired using a Bruker Alpha spectrometer with a Platinum ATR singlereflection diamond ATR module. For this analysis, a piece of the vacuum-filtered membrane was pressed against the diamond, and the spectra were recorded over 24 scans. The spectra were smoothed and baseline-corrected using Bruker Opus 7.2 software. High-resolution TEM was conducted on a Hitachi HT 7700 system. The samples were prepared by diluting and briefly sonicating an EGO DMF dispersion e and then drop-casting the dispersion onto a copper grid. TGA was performed on a Netzsch STA 449F3 analyzer in either an argon atmosphere or a $20 \%$ oxygen $/ 80 \%$ argon gas environment. In either case, the temperature was first ramped to $50{ }^{\circ} \mathrm{C}$ at a rate of $40 \mathrm{~K} / \mathrm{min}$ and then held at $50{ }^{\circ} \mathrm{C}$ for $2.5 \mathrm{~h}$. Subsequently, the temperature was ramped to the final temperature at a rate of $5 \mathrm{~K} / \mathrm{min}$ (for the oxygen atmosphere experiment) or $10 \mathrm{~K} / \mathrm{min}$ (for the argon atmosphere experiment). The electrical conductivity measurements for the EGO and CGO films were carried out on a Jandel RM3000 four-point probe system with a linear-arrayed head (probe spacing of $1 \mathrm{~mm}$ ). A total of 30 measurements were taken for each $\sim 20 \mu \mathrm{m}$ film. We note that, like CGO, the conductivity of the EGO films gradually increases over time when stored in the dried state. Therefore, conductivity measurements were performed on freshly cast membranes.

For the thermal treatment study, four 13-mm-diameter disks weighing $3-5 \mathrm{mg}$ initially were punched from a vacuum-filtered membrane. The disks were then placed in a standard laboratory oven in an air atmosphere at $200{ }^{\circ} \mathrm{C}$. The disks were sequentially removed after $5 \mathrm{~min}, 10 \mathrm{~min}, 1 \mathrm{~h}$, and $4 \mathrm{~h}$. Both before and after the thermal treatment, the disks were weighed with an analytical balance, their sheet resistances measured using the four-point probe, and their thicknesses measured using a digital outside micrometer. Raman, FTIR, and XRD were carried out on the heat-treated disks as described above.

LIB Testing. For preparation of the control LIB cathodes, $10 \mathrm{wt} \%$ PVDF, $10 \mathrm{wt} \% \mathrm{CB}$, and $80 \mathrm{wt} \%$ of the active material, LFP, were mixed with $N$-methyl-2-pyrrolidone (NMP) by grinding in a mortar and pestle for $30 \mathrm{~min}$ and then stirred for $3 \mathrm{~h}$. The resultant slurry, coated on an aluminum foil, was dried at $80{ }^{\circ} \mathrm{C}$ for $12 \mathrm{~h}$ in air. The coin cells (2032) were assembled in an argon-filled glovebox using a lithium foil as the anode and $1 \mathrm{M} \mathrm{LiPF}_{6}$ dissolved in ethylene carbonate, dimethyl carbonate, and ethyl methyl carbonate with a volume ratio of 1:1:1 as the electrolyte. A schematic of the coin cell is shown in Figure S25. Cells were tested at ambient temperature. The testing voltage in the constant-current mode was between 2.5 and 3.8 $\mathrm{V}$, and the cells were charged in the constant-voltage mode at $3.8 \mathrm{~V}$ until the current reached $10 \%$ of the current rate. Battery tests were performed on a Land CT2001A battery tester.

For the experimental conditions, $50 \mathrm{wt} \%$ of the $\mathrm{CB}$ amount was replaced with EGO, such that EGO made up 5\% of the total cathode mass. To prepare the EGO, the product was purified as described above and then shear-mixed at low speed for $20 \mathrm{~min}$ at a concentration of $0.3 \mathrm{mg} / \mathrm{mL}$ in water adjusted to $\mathrm{pH} 10$ with ammonia added to improve the dispersibility. After it was freeze-dried for storage, the EGO was redispersed in water. The $\mathrm{pH}$ was adjusted to 12 with ammonia, and the solution was probe-sonicated for $2 \mathrm{~h}$ in an ice bath. The product was freeze-dried to remove water before being combined with the other cathode materials by grinding in $\mathrm{NMP}$, as described above. As above, the cathodes were dried at $80^{\circ} \mathrm{C}$ for $12 \mathrm{~h}$ in air. To improve its conductivity, the cathode was then heat-treated by placing it in an oven at room temperature in an air atmosphere, ramping the temperature to $200{ }^{\circ} \mathrm{C}$ at $5{ }^{\circ} \mathrm{C} / \mathrm{min}$, and then holding the temperature at $200{ }^{\circ} \mathrm{C}$ for $10 \mathrm{~min}$.

\section{ASSOCIATED CONTENT}

\section{S Supporting Information}

The Supporting Information is available free of charge on the ACS Publications website at DOI: 10.1021/acsanm.8b02126. 
Additional figures (Figures S1-S32), tables (Tables S1S8) and supplementary notes (PDF)

\section{AUTHOR INFORMATION}

\section{Corresponding Authors}

*E-mail: y.zhong@griffith.edu.au.

*E-mail: h.zhao@griffith.edu.au.

\section{ORCID $\odot$}

Shujun Wang: 0000-0003-4377-2791

Mohammad Al-Mamun: 0000-0001-8201-4278

Porun Liu: 0000-0002-0046-701X

Yu Lin Zhong: 0000-0001-6741-3609

Huijun Zhao: 0000-0003-3794-4497

\section{Notes}

The authors declare no competing financial interest.

\section{ACKNOWLEDGMENTS}

This work was supported by the Australian Research Council (Grant DP170104157). D.Q. acknowledges support of the Australian Research Council (Grant FT160100207). Part of this research was undertaken on the soft X-ray spectroscopy beamline at the Australian Synchrotron, part of the Australian Nuclear Science and Technology Organisation.

\section{REFERENCES}

(1) Dreyer, D. R.; Todd, A. D.; Bielawski, C. W. Harnessing the Chemistry of Graphene Oxide. Chem. Soc. Rev. 2014, 43, 5288-5301.

(2) Huang, L.; Huang, Y.; Liang, J.; Wan, X.; Chen, Y. GrapheneBased Conducting Inks for Direct Inkjet Printing of Flexible Conductive Patterns and Their Applications in Electric Circuits and Chemical Sensors. Nano Res. 2011, 4, 675-684.

(3) Huang, W. T.; Luo, H. Q.; Li, N. B. Boolean Logic Tree of Graphene-Based Chemical System for Molecular Computation and Intelligent Molecular Search Query. Anal. Chem. 2014, 86, 44944500 .

(4) Huang, W. T.; Shi, Y.; Xie, W. Y.; Luo, H. Q.; Li, N. B. A Reversible Fluorescence Nanoswitch Based on Bifunctional Reduced Graphene Oxide: Use for Detection of $\mathrm{Hg}^{2+}$ and Molecular Logic Gate Operation. Chem. Commun. 2011, 47, 7800-7802.

(5) Lu, J. Y.; Zhang, X. X.; Zhu, Q. Y.; Zhang, F. R.; Huang, W. T.; Ding, X. Z.; Xia, L. Q.; Luo, H. Q.; Li, N. B. Highly Tunable and Scalable Fabrication of 3D Flexible Graphene Micropatterns for Directing Cell Alignment. ACS Appl. Mater. Interfaces 2018, 10, 17704-17713.

(6) Sun, J.; Yang, D.; Lowe, S.; Zhang, L.; Wang, Y.; Zhao, S.; Liu, P.; Wang, Y.; Tang, Z.; Zhao, H.; Yao, X. Sandwich-Like Reduced Graphene Oxide/Carbon Black/Amorphous Cobalt Borate Nanocomposites as Bifunctional Cathode Electrocatalyst in Rechargeable Zinc-Air Batteries. Adv. Energy Mater. 2018, 8, 1801495.

(7) Sun, J.; Yin, H.; Liu, P.; Wang, Y.; Yao, X.; Tang, Z.; Zhao, H. Molecular Engineering of $\mathrm{Ni}-/ \mathrm{Co}-$ Porphyrin Multilayers on Reduced Graphene Oxide Sheets as Bifunctional Catalysts for Oxygen Evolution and Oxygen Reduction Reactions. Chem. Sci. 2016, 7, $5640-5646$.

(8) Stankovich, S.; Dikin, D. A.; Dommett, G. H. B.; Kohlhaas, K. M.; Zimney, E. J.; Stach, E. A.; Piner, R. D.; Nguyen, S. T.; Ruoff, R. S. Graphene-Based Composite Materials. Nature 2006, 442, 282-286.

(9) Pumera, M. Graphene-Based Nanomaterials for Energy Storage. Energy Environ. Sci. 2011, 4, 668-674.

(10) Zurutuza, A.; Marinelli, C. Challenges and Opportunities in Graphene Commercialization. Nat. Nanotechnol. 2014, 9, 730-734.

(11) Hummers, W. S.; Offeman, R. E. Preparation of Graphitic Oxide. J. Am. Chem. Soc. 1958, 80, 1339-1339.

(12) Lowe, S. E.; Zhong, Y. Challenges of Industrial-Scale Graphene Oxide Production. In Graphene Oxide. Fundamentals and Applications;
Dimiev, A. M., Eigler, S., Eds.; John Wiley \& Sons: Oxford, U.K., 2015.

(13) Zhong, Y. L.; Tian, Z.; Simon, G. P.; Li, D. Scalable Production of Graphene via Wet Chemistry: Progress and Challenges. Mater. Today 2015, 18, 73-78.

(14) Koch, K. R.; Krause, P. F. Oxidation by $\mathrm{Mn}_{2} \mathrm{O}_{7}$ : An Impressive Demonstration of the Powerful Oxidizing Property of Dimanganeseheptoxide. J. Chem. Educ. 1982, 59, 973-974.

(15) Yu, P.; Lowe, S. E.; Simon, G. P.; Zhong, Y. L. Electrochemical Exfoliation of Graphite and Production of Functional Graphene. Curr. Opin. Colloid Interface Sci. 2015, 20, 329-338.

(16) Singh, V. V.; Gupta, G.; Batra, A.; Nigam, A. K.; Boopathi, M.; Gutch, P. K.; Tripathi, B. K.; Srivastava, A.; Samuel, M.; Agarwal, G. S.; Singh, B.; Vijayaraghavan, R. Greener Electrochemical Synthesis of High Quality Graphene Nanosheets Directly from Pencil and Its SPR Sensing Application. Adv. Funct. Mater. 2012, 22, 2352-2362.

(17) Cao, J.; He, P.; Mohammed, M. A.; Zhao, X.; Young, R. J.; Derby, B.; Kinloch, I. A.; Dryfe, R. A. W. Two-Step Electrochemical Intercalation and Oxidation of Graphite for the Mass Production of Graphene Oxide. J. Am. Chem. Soc. 2017, 139, 17446-17456.

(18) Parvez, K.; Rincón, R. A.; Weber, N.-E.; Cha, K. C.; Venkataraman, S. One-Step Electrochemical Synthesis of Nitrogen and Sulfur Co-Doped, High-Quality Graphene Oxide. Chem. Commun. 2016, 52, 5714-5717.

(19) Abdelkader, A. M.; Kinloch, I. A.; Dryfe, R. A. W. High-Yield Electro-Oxidative Preparation of Graphene Oxide. Chem. Commun. 2014, 50, 8402-8404.

(20) Pei, S.; Wei, Q.; Huang, K.; Cheng, H.-M.; Ren, W. Green Synthesis of Graphene Oxide by Seconds Timescale Water Electrolytic Oxidation. Nat. Commun. 2018, 9, 145.

(21) Tian, Z.; Yu, P.; Lowe, S. E.; Pandolfo, A. G.; Gengenbach, T. R.; Nairn, K. M.; Song, J.; Wang, X.; Zhong, Y. L.; Li, D. Facile Electrochemical Approach for the Production of Graphite Oxide with Tunable Chemistry. Carbon 2017, 112, 185-191.

(22) Parvez, K.; Li, R.; Puniredd, S. R.; Hernandez, Y.; Hinkel, F.; Wang, S.; Feng, X.; Müllen, K. Electrochemically Exfoliated Graphene as Solution-Processable, Highly Conductive Electrodes for Organic Electronics. ACS Nano 2013, 7, 3598-3606.

(23) Rao, K. S.; Sentilnathan, J.; Cho, H.-W.; Wu, J.-J.; Yoshimura, M. Soft Processing of Graphene Nanosheets by Glycine-Bisulfate Ionic-Complex-Assisted Electrochemical Exfoliation of Graphite for Reduction Catalysis. Adv. Funct. Mater. 2015, 25, 298-305.

(24) Gurzęda, B.; Florczak, P.; Kempiński, M.; Peplińska, B.; Krawczyk, P.; Jurga, S. Synthesis of Graphite Oxide by Electrochemical Oxidation in Aqueous Perchloric Acid. Carbon 2016, 100, 540-545.

(25) Gurzęda, B.; Buchwald, T.; Nocuń, M.; Bąkowicz, A.; Krawczyk, P. Graphene Material Preparation through Thermal Treatment of Graphite Oxide Electrochemically Synthesized in Aqueous Sulfuric Acid. RSC Adv. 2017, 7, 19904-19911.

(26) Yu, P.; Tian, Z.; Lowe, S. E.; Song, J.; Ma, Z.; Wang, X.; Han, Z. J.; Bao, Q.; Simon, G. P.; Li, D.; Zhong, Y. L. Mechanically-Assisted Electrochemical Production of Graphene Oxide. Chem. Mater. 2016, 28, 8429-8438.

(27) Parvez, K.; Wu, Z. S.; Li, R.; Liu, X.; Graf, R.; Feng, X.; Müllen, K. Exfoliation of Graphite into Graphene in Aqueous Solutions of Inorganic Salts. J. Am. Chem. Soc. 2014, 136, 6083-6091.

(28) Symes, M. D.; Kitson, P. J.; Yan, J.; Richmond, C. J.; Cooper, G. J.; Bowman, R. W.; Vilbrandt, T.; Cronin, L. Integrated 3D-Printed Reactionware for Chemical Synthesis and Analysis. Nat. Chem. 2012, 4, 349-354.

(29) Sorokina, N.; Maksimova, N.; Avdeev, V. Anodic Oxidation of Graphite in 10 to $98 \% \mathrm{HNO}_{3}$. Inorg. Mater. 2001, 37, 360-365.

(30) Yakovlev, A.; Finaenov, A.; Zabud'kov, S.; Yakovleva, E. Thermally Expanded Graphite: Synthesis, Properties, and Prospects for Use. Russ. J. Appl. Chem. 2006, 79, 1741-1751.

(31) Zhong, Y. L.; Ng, W.; Yang, J.-X.; Loh, K. P. Electrostatically Self-Assembled Polyoxometalates on Molecular-Dye-Functionalized Diamond. J. Am. Chem. Soc. 2009, 131, 18293-18298. 
(32) Zhong, Y. L.; Midya, A.; Ng, Z.; Chen, Z.-K.; Daenen, M.; Nesladek, M.; Loh, K. P. Diamond-Based Molecular Platform for Photoelectrochemistry. J. Am. Chem. Soc. 2008, 130, 17218-17219.

(33) Cobb, S. J.; Ayres, Z. J.; Macpherson, J. V. Boron Doped Diamond: A Designer Electrode Material for the Twenty-First Century. Annu. Rev. Anal. Chem. 2018, 11, 463-484.

(34) Beck, F.; Jiang, J.; Krohn, H. Potential Oscillations During Galvanostatic Overoxidation of Graphite in Aqueous Sulphuric Acids. J. Electroanal. Chem. 1995, 389, 161-165.

(35) Kang, F.; Zhang, T.-Y.; Leng, Y. Electrochemical Behavior of Graphite in Electrolyte of Sulfuric and Acetic Acid. Carbon 1997, 35, $1167-1173$.

(36) Besenhard, J.; Wudy, E.; Möhwald, H.; Nickl, J.; Biberacher, W.; Foag, W. Anodic Oxidation of Graphite in $\mathrm{H}_{2} \mathrm{SO}_{4}$ Dilatometryin Situ X-Ray Diffraction-Impedance Spectroscopy. Synth. Met. 1983, 7, 185-192.

(37) Nakajima, T.; Matsuo, Y. Formation Process and Structure of Graphite Oxide. Carbon 1994, 32, 469-475.

(38) Metrot, A.; Fischer, J. E. Charge Transfer Reactions During Anodic Oxidation of Graphite in $\mathrm{H}_{2} \mathrm{SO}$. Synth. Met. 1981, 3, 201207.

(39) Park, S.; An, J.; Potts, J. R.; Velamakanni, A.; Murali, S.; Ruoff, R. S. Hydrazine-Reduction of Graphite- and Graphene Oxide. Carbon 2011, 49, 3019-3023.

(40) Shen, J.; Hu, Y.; Shi, M.; Lu, X.; Qin, C.; Li, C.; Ye, M. Fast and Facile Preparation of Graphene Oxide and Reduced Graphene Oxide Nanoplatelets. Chem. Mater. 2009, 21, 3514-3520.

(41) Sorokina, N.; Khaskov, M.; Avdeev, V.; Nikol'Skaya, I. Reaction of Graphite with Sulfuric Acid in the Presence of $\mathrm{KMnO}_{4}$. Russ. J. Gen. Chem. 2005, 75, 162-168.

(42) Bard, A. J.; Inzelt, G.; Scholz, F. Electrochemical Dictionary; Springer: Berlin, 2008.

(43) Dimiev, A.; Kosynkin, D. V.; Alemany, L. B.; Chaguine, P.; Tour, J. M. Pristine Graphite Oxide. J. Am. Chem. Soc. 2012, 134, 2815-2822.

(44) Marcano, D. C.; Kosynkin, D. V.; Berlin, J. M.; Sinitskii, A.; Sun, Z.; Slesarev, A.; Alemany, L. B.; Lu, W.; Tour, J. M. Improved Synthesis of Graphene Oxide. ACS Nano 2010, 4, 4806-4814.

(45) Eigler, S.; Dimiev, A., Characterization Techniques. In Graphene Oxide; Dimiev, A., Eigler, S., Eds.; John Wiley \& Sons, 2016.

(46) Wu, J.-B.; Lin, M.-L.; Cong, X.; Liu, H.-N.; Tan, P.-H. Raman Spectroscopy of Graphene-Based Materials and Its Applications in Related Devices. Chem. Soc. Rev. 2018, 47, 1822-1873.

(47) Eigler, S. Graphite Sulphate - a Precursor to Graphene. Chem. Commun. 2015, 51, 3162-3165.

(48) Sadezky, A.; Muckenhuber, H.; Grothe, H.; Niessner, R.; Pöschl, U. Raman Microspectroscopy of Soot and Related Carbonaceous Materials: Spectral Analysis and Structural Information. Carbon 2005, 43, 1731-1742.

(49) Herdman, J. D.; Connelly, B. C.; Smooke, M. D.; Long, M. B.; Miller, J. H. A Comparison of Raman Signatures and Laser-Induced Incandescence with Direct Numerical Simulation of Soot Growth in Non-Premixed Ethylene/Air Flames. Carbon 2011, 49, 5298-5311.

(50) Goodman, P. A.; Li, H.; Gao, Y.; Lu, Y. F.; Stenger-Smith, J. D.; Redepenning, J. Preparation and Characterization of High Surface Area, High Porosity Carbon Monoliths from Pyrolyzed Bovine Bone and Their Performance as Supercapacitor Electrodes. Carbon 2013, 55, 291-298.

(51) Claramunt, S.; Varea, A.; López-Díaz, D.; Velázquez, M. M.; Cornet, A.; Cirera, A. The Importance of Interbands on the Interpretation of the Raman Spectrum of Graphene Oxide. J. Phys. Chem. C 2015, 119, 10123-10129.

(52) Dimiev, A. M.; Alemany, L. B.; Tour, J. M. Graphene Oxide. Origin of Acidity, Its Instability in Water, and a New Dynamic Structural Model. ACS Nano 2013, 7, 576-588.

(53) Acik, M.; Lee, G.; Mattevi, C.; Chhowalla, M.; Cho, K.; Chabal, Y. J. Unusual Infrared-Absorption Mechanism in Thermally Reduced Graphene Oxide. Nat. Mater. 2010, 9, 840-845.
(54) Dresselhaus, M. S.; Dresselhaus, G. Intercalation Compounds of Graphite. Adv. Phys. 2002, 51, 1-186.

(55) Alsmeyer, D. C.; McCreery, R. L. In Situ Raman Monitoring of Electrochemical Graphite Intercalation and Lattice Damage in Mild Aqueous Acids. Anal. Chem. 1992, 64, 1528-1533.

(56) Shioyama, H.; Fujii, R. Electrochemical Reactions of Stage 1 Sulfuric Acid-Graphite Intercalation Compound. Carbon 1987, 25, $771-774$.

(57) Kang, F.; Zhang, T.-Y.; Leng, Y. Electrochemical Synthesis of Sulfate Graphite Intercalation Compounds with Different Electrolyte Concentrations. J. Phys. Chem. Solids 1996, 57, 883-888.

(58) Eigler, S. Graphite Sulphate - a Precursor to Graphene. Chem. Commun. 2015, 51, 3162-3165.

(59) Dimiev, A. M. Mechanism of Formation and Chemical Structure of Graphene Oxide. In Graphene Oxide; John Wiley \& Sons, Ltd., 2016; pp 36-84.

(60) Jnioui, A.; Metrot, A.; Storck, A. Electrochemical Production of Graphite Salts Using a Three-Dimensional Electrode of Graphite Particles. Electrochim. Acta 1982, 27, 1247-1252.

(61) Pan, Q.; Chung, C.-C.; He, N.; Jones, J. L.; Gao, W. Accelerated Thermal Decomposition of Graphene Oxide Films in Air via in Situ X-Ray Diffraction Analysis. J. Phys. Chem. C 2016, 120, 14984-14990.

(62) Wang, Z.-1.; Xu, D.; Huang, Y.; Wu, Z.; Wang, L.-m.; Zhang, X.b. Facile, Mild and Fast Thermal-Decomposition Reduction of Graphene Oxide in Air and Its Application in High-Performance Lithium Batteries. Chem. Commun. 2012, 48, 976-978.

(63) Larciprete, R.; Fabris, S.; Sun, T.; Lacovig, P.; Baraldi, A.; Lizzit, $S$. Dual Path Mechanism in the Thermal Reduction of Graphene Oxide. J. Am. Chem. Soc. 2011, 133, 17315-17321.

(64) Grote, F.; Gruber, C.; Börrnert, F.; Kaiser, U.; Eigler, S. Thermal Disproportionation of Oxo-Functionalized Graphene. Angew. Chem., Int. Ed. 2017, 56, 9222-9225.

(65) Kumar, P. V.; Bardhan, N. M.; Tongay, S.; Wu, J.; Belcher, A. M.; Grossman, J. C. Scalable Enhancement of Graphene Oxide Properties by Thermally Driven Phase Transformation. Nat. Chem. 2014, 6, 151-158.

(66) Huang, Y.; Liu, H.; Lu, Y.-C.; Hou, Y.; Li, Q. Electrophoretic Lithium Iron Phosphate/Reduced Graphene Oxide Composite for Lithium Ion Battery Cathode Application. J. Power Sources 2015, 284, 236-244.

(67) Liu, Y.; Liu, D.; Zhang, Q.; Yu, D.; Liu, J.; Cao, G. Lithium Iron Phosphate/Carbon Nanocomposite Film Cathodes for High Energy Lithium Ion Batteries. Electrochim. Acta 2011, 56, 2559-2565.

(68) Hu, L.-H.; Wu, F.-Y.; Lin, C.-T.; Khlobystov, A. N.; Li, L.-J. Graphene-Modified $\mathrm{LiFePO}_{4}$ Cathode for Lithium Ion Battery Beyond Theoretical Capacity. Nat. Commun. 2013, 4, 1687.

(69) Yang, S.; Ricciardulli, A. G.; Liu, S.; Dong, R.; Lohe, M. R.; Becker, A.; Squillaci, M. A.; Samorì, P.; Müllen, K.; Feng, X. Ultrafast Delamination of Graphite into High-Quality Graphene Using Alternating Currents. Angew. Chem., Int. Ed. 2017, 56, 6669-6675.

(70) Kovtyukhova, N. I.; Ollivier, P. J.; Martin, B. R.; Mallouk, T. E.; Chizhik, S. A.; Buzaneva, E. V.; Gorchinskiy, A. D. Layer-by-Layer Assembly of Ultrathin Composite Films from Micron-Sized Graphite Oxide Sheets and Polycations. Chem. Mater. 1999, 11, 771-778. 